\title{
An interjurisdictional approach to designing residual risk policy
}

\author{
A Shrivathsa Queensland Government, Australia \\ S Cooper Queensland Government, Australia
}

\begin{abstract}
In late February this year, the Queensland Government hosted 40 government delegates from New South Wales, Victoria and the Northern Territory for a 2.5-day workshop discussing government policy on residual risks in the resource industry. Residual risks of post-closure management are considered those risks that remain on a site after surrender of the resource and/or environmental authority or permit. These could include the potential for a credible risk event occurring and requiring rectification and ongoing monitoring and maintenance requirements. Government representatives from environmental and mining regulation departments shared information, research and results of consultation through presentations and discussions. Through facilitated workshops, government officials identified common issues and worked to develop potential solutions. A major outcome of the workshop was a set of guiding principles available to all Australian jurisdictions, when developing or implementing residual risk policy. At this stage, the principles should not be taken to be current government policy. This presentation and paper will give conference attendees an overview of the issues raised throughout the workshop, the outcomes and next steps.
\end{abstract}

Keywords: residual risk, rehabilitation, collaboration, policy development, post-closure

\section{Introduction}

The interjurisdictional workshop on managing residual risks (the workshop) was held from 27 February 2019 to 1 March 2019. All Australian state and territory jurisdictions were invited and officers from the Northern Territory, Queensland, New South Wales and Victoria attended the workshop, which was designed by officers at the Queensland Department of Environment and Science in conjunction with facilitators, JTA Australia.

The 2.5-day workshop aimed to achieve the objectives of sharing information about current residual risk related projects, identifying common issues, opportunities and solutions and developing guiding principles to support coherent residual risk policymaking across Australia. The workshop also allowed jurisdictions to work across borders, just as companies undertaking resource activities do.

In Queensland 'residual risks' are those that remain at a rehabilitated and surrendered resource site, when the resource company is generally no longer responsible for the monitoring, maintenance or rectification of the site. Residual risks can also be termed as 'post-closure management' in other jurisdictions-for the purposes of this paper, we will generally use the term residual risk.

Following surrender, there may be ongoing requirements to monitor aspects of the site and manage engineered structures to ensure they continue to meet their design function. There may also be a need to rectify any subsequent rehabilitation failures that occur after surrender. The intent of a residual risk or post-closure policy framework is to make clear how these risks and obligations are managed between industry, government and landholders. In some jurisdictions, these risks may be managed by the state or territory government.

The workshop was designed and facilitated to ensure that all jurisdictions gained information and tools that enabled them to consider a common approach to managing these residual risks. Jurisdictions were asked to 
provide pre-workshop reading and presentations to prepare all participants with knowledge of the frameworks that each jurisdiction operates within.

\subsection{Jurisdictional differences}

To facilitate a baseline level of knowledge among workshop attendees each jurisdiction prepared preworkshop reading. Jurisdictions were asked to provide information on the frameworks that regulate resource activities and any current or potential residual risk policy.

It was quite clear prior to the workshop that each participating jurisdiction was at a different stage of residual risk policy development. Through the pre-workshop reading and information sharing on Day 1 , all participants gained a consistent level of knowledge to collaborate during Day 2 and Day 3 of the workshop.

This section provides a summary of the status of residual risk policy in each jurisdiction along with any relevant rehabilitation policy matters.

\subsubsection{Queensland}

In Queensland, residual risk policy is being considered as part of a whole-of-government financial assurance reform program. Queensland identified that managing the environmental and financial risks of resource activities required policy work on a number of fronts. The development of the residual risk policy has followed the development of a mined land rehabilitation policy and new financial provisioning scheme; see Cooper (2019) for more information on the development of these policies.

Currently, the residual risk requirements in Queensland become relevant once all obligations and criteria associated with the surrender framework are met. Consideration of residual risks is required for partial or full surrender applications. The residual risk requirements do not remove or change the obligations of an environmental authority holder to complete rehabilitation to required standards.

The residual risk framework will enable companies to surrender the tenure and environmental authority while ensuring that the state understands any remaining risks onsite, it has a management plan for those risks, and it is resourced to manage them.

On 19 November 2018, the Queensland Government released the Managing Residual Risks in Queensland discussion paper (residual risk paper). The residual risk paper outlined the current residual risk requirements and indicated how they sit within the broader environmental regulation framework (State of Queensland 2018). It also clarified the distinction between environmental authority obligations and post-surrender management requirements. The public consultation period closed on 1 February 2019 with 12 submissions received.

The residual risk paper provided a number of proposals and clarifications, which included principles to be used in developing a standardised risk assessment methodology, options to assist with the estimation of post-surrender costs, clarification of payment requirements, identification of the need to record postsurrender management activities and identification of key roles in the post-surrender management of land and funds.

\subsubsection{New South Wales}

In New South Wales, residual risk policy is currently under consideration as part of the overall regulatory framework for mine rehabilitation, including its relevance to the existing framework, which is designed to minimise risk upfront. The Department of Planning and Environment does not hold any financial assurance to cover the costs associated with mitigating future environmental degradation once a project closes and the security deposit is relinquished. However, there are powers available to the relevant regulator under New South Wales resources legislation to enforce environmental and rehabilitation obligations and hold security deposits after a title ceases to have effect. The Environment Protection Authority can also require financial assurance as a condition on an environmental protection licence, including as a condition on surrender of the licence, for carrying out licensed works such as remediation work or pollution reduction programs. 
To construct and operate a mineral or petroleum project in New South Wales, the developer must apply for and obtain development consent under the Environmental Planning and Assessment Act 1979 (Government of New South Wales 1979). The consent authority must evaluate the potential environmental, social and economic impacts associated with the development application. The Environmental Impact Statement, which accompanies the development application, must include a description of the rehabilitation proposal and proposed post-closure land use outcomes.

The holder of a mining or petroleum production lease must submit more detailed rehabilitation plans, objectives and completion criteria for approval by the regulator. These plans describe what rehabilitation works will be completed and when, and require rehabilitation to be completed progressively. The holder of a mining or petroleum production lease must also lodge a rehabilitation security deposit with the Division of Resources and Geoscience.

The security deposit must cover the government's full costs in undertaking rehabilitation in the event of default by the leaseholder. This requirement minimises potential liabilities to the state in the event that the holder of the mining lease fails to deliver their rehabilitation obligations. If this happens, the government can use the security deposit to rehabilitate the site.

The holder of the mining or petroleum production lease must demonstrate that rehabilitation objectives and completion criteria have been met as part of any request to relinquish the lease. Under current practices, the security deposit is not returned, and the lease is not cancelled, until the Department of Planning and Environment-Resources Regulator determines that the leaseholder has met all rehabilitation objectives and completion criteria, addressed significant risks and that areas disturbed by mining operations are returned to a condition capable of achieving the approved final land use/s.

\subsubsection{Northern Territory}

The Northern Territory Government is reviewing and reforming the entire current environmental regulatory system. A single piece of legislation is being developed to implement a reformed environmental management regulatory framework - the proposed 'Environment Protection Act'. Development of the Act, and the reform program, has been separated into two stages.

The first stage will reform the environmental impact assessment process and introduce a new environmental approval that may be granted by the Minister for Environment and Natural Resources at the completion of the assessment process. The draft Environment Protection Bill and Regulations for Stage 1 were released for consultation on 4 October and concluded 2 December 2018.

As part of the second stage of reforms, the Northern Territory Government has determined that environmental regulation of mining activities (currently contained in the Mining Management Act 2001 [Government of Northern Territory 2001] administered by the Department of Primary Industry and Resources) will be transferred from the Mining Management Act to the new Environment Protection Bill and Regulations administered by the Department of Environment and Natural Resources (DENR). In this reform context, DENR is currently exploring policy options in the management of residual risks both within the mining regulation framework and for other non-mining activities that will be regulated under the new Act.

The process for surrender of authorisation currently is integrated into review and update of the Mining Management Plan. The Department of Primary Industry and Resources (DPIR) uses broad evaluation criteria to assess whether the site has been successfully rehabilitated. To apply to close a mining site, an operator applies for a certificate of closure and must include a rehabilitation report that describes the completed rehabilitation work.

Current arrangements under the Mining Management Act do not explicitly acknowledge or address residual risks. DPIR may broaden the purpose of the mining remediation fund to allow expenditure on minimising or rectifying environmental harm from any mining activity once a closure certificate has been issued in order to address residual risks. 


\subsubsection{Victoria}

In Victoria, the phase following licence relinquishment and rehabilitation is referred to as 'post-closure', and the associated risks are referred to as 'post-closure risks'. 'Residual risks' are the risks remaining after a schedule of monitoring and maintenance of rehabilitated landforms has been set out, rather than all risks and costs that exist after rehabilitation is complete.

Much of the consideration of post-closure management policy is in response to the Hazelwood Mine Fire Inquiry (the Inquiry). The Inquiry found that the legislative and regulatory framework for rehabilitation and post-closure management was unclear, inefficient and deficient. It also found there was an urgent need for a coordinating body to exist outside of government that could provide advice, monitor the implementation of strategies, facilitate community involvement, undertake audits, conduct investigations, and share and publish information related to mine rehabilitation.

The Inquiry recommended that an independent Mine Rehabilitation Commissioner be set up that, among other functions, should have the ability to carry out strategic audits of public sector bodies and Latrobe Valley licensees in relation to rehabilitation planning activities. The Inquiry recommended that the Commissioner be later subsumed into a statutory mine rehabilitation authority to provide greater coordination and oversight required due to increasing complexity of rehabilitation on a regional scale (Hazelwood Mine Fire Inquiry 2016).

The Mineral Resources (Sustainable Development) Amendment (Latrobe Valley Mine Rehabilitation Commissioner) Bill 2017 was introduced and passed in May 2017 to establish the statutory office of the Commissioner to monitor and audit mine rehabilitation, and consult local communities. Emeritus Professor Rae Mackay commenced in the Commissioner role in June 2017.

In 2018, the Victorian Government introduced the Mineral Resources (Sustainable Development) Amendment Bill 2018 (Amendment Bill), which did not pass into law before the Parliament was dissolved prior to the 2018 election. Should the Amendment Bill be reintroduced in 2019, it will establish a Mine Land Rehabilitation Authority (MLRA) and clarify the regulatory requirements for mine rehabilitation and postclosure management from June 2020. The MLRA will provide information to the community and advise regulators and government agencies on declared mine land rehabilitation and post-closure management, to ensure a safe and stable landform is achieved and maintained.

Post-closure management is considered the final stage of a mine's life, commencing at the end of rehabilitation. Post-closure plans are required to inform decisions on acceptance of post-mining land use(s) and landform(s), completion criteria and ongoing costs and risks. Post-closure payments become a condition of relinquishment or land ownership transfer. Where rehabilitation seeks to reduce risks to an acceptable level, post-closure management aims to maintain the agreed risk levels or reduce them in the longer term though scheduled monitoring and maintenance, or repairs following unforeseen events.

The MLRA will also be empowered to take ownership of rehabilitated mine land, and to administer postclosure plans, the Declared Mine Fund and the associated Declared Mine Land Registry. Under the proposed framework, post-closure plans are attached to registered land. The Declared Mine Fund is a postclosure trust fund to hold post-closure payments and is drawn upon to undertake scheduled monitoring and maintenance and mitigate post-closure risks. The fund can be made up of contributions from mine operators, rehabilitation bonds and the government. The post-closure payment will cover costs of ongoing land management and will likely include a net present value estimate of monitoring and maintenance, and an estimate of 'residual risks' that arise from the rehabilitated landform.

The Victorian Government has also recently released draft Mineral Resources (Sustainable Development) (Mineral Industries) Regulations 2019 (Minerals Regulations) (Government of Victoria 2019). The Minerals Regulations include a requirement that all new and varied rehabilitation plans identify risks likely to arise from rehabilitated land, activities to manage those risks and an estimate of the cost. This is being introduced to require rehabilitation plans to include estimates of post-closure risks to inform better decisions around acceptable rehabilitation completion criteria and rehabilitation landforms. 


\section{Process}

\subsection{Pre-workshop}

The workshop was initially devised following discussions with Victoria regarding rehabilitation policy work. Further discussions lead to the inclusion of all jurisdictions, with New South Wales, Victoria and the Northern Territory being able to attend. Other jurisdictions, that were unable to attend, were keen to see the outcomes of the workshop and potentially be involved in future discussions about residual risk policy.

As outlined in Section 1.1, each Australian state and territory has different frameworks in which resource activities are undertaken and have different drivers and magnitudes of residual risk. The pre-reading requested from each jurisdiction, detailed each jurisdiction's current rehabilitation frameworks, policies, and any current or potential future policy on managing residual risks.

Jurisdictions were also asked to nominate their top five issues from the following list, the five issues underlined were chosen:

- Expert panel: How is it triggered, who is it composed of, et cetera?

- Cost estimate and potential calculation methodologies.

- Post-surrender land administration: Who, how?

- Land Access: Who, how?

- Post-surrender land management plan: What is in it, how does it get implemented?

- Fund administration/management: Who, how?

- Transferring assets to landholders: Should assets still be considered in residual risk payment?

- What site features should be considered?

\subsection{Workshop structure}

In structuring the workshop, the Queensland Department of Environment and Science took an innovative approach, harnessing the double diamond framework and design thinking processes to assist in achieving the best outcomes from the workshop. These methodologies are explained in more detail in this section.

\subsubsection{Double diamond framework}

The double diamond process displays the convergent and divergent stages of a design process. The framework was created by The UK Design Council. Creative thinking processes employ divergent thinking, to create a number of possible ideas before using convergent thinking to refine the best ideas. The double diamond specifies that this happens, or should happen, twice: once to properly define the problem and once to develop the solution (The UK Design Council 2015).

Working this way means that solutions address the right problem and have been refined prior to implementation.

Figure 1 shows the double diamond framework and the way it was used within the context of the workshop. The double diamond framework allowed the workshop to achieve its three objectives of sharing information about current residual risk related projects, identifying common issues, opportunities and solutions and developing guiding principles to support coherent residual risk policy making across Australia. The workshop pre-reading and the presentations on Day 1 covered the 'discover' stage, gaining insight from participating jurisdictions on current frameworks and policy. Day 2 covered the 'define' and 'develop' stages, using design thinking to define the problem, investigating why the problem exists and why it should be solved, and what the opportunities were within the problem. Day 3 covered the 'deliver' stage, refining the three best options from Day 2 into guiding principles for all jurisdictions to use. 


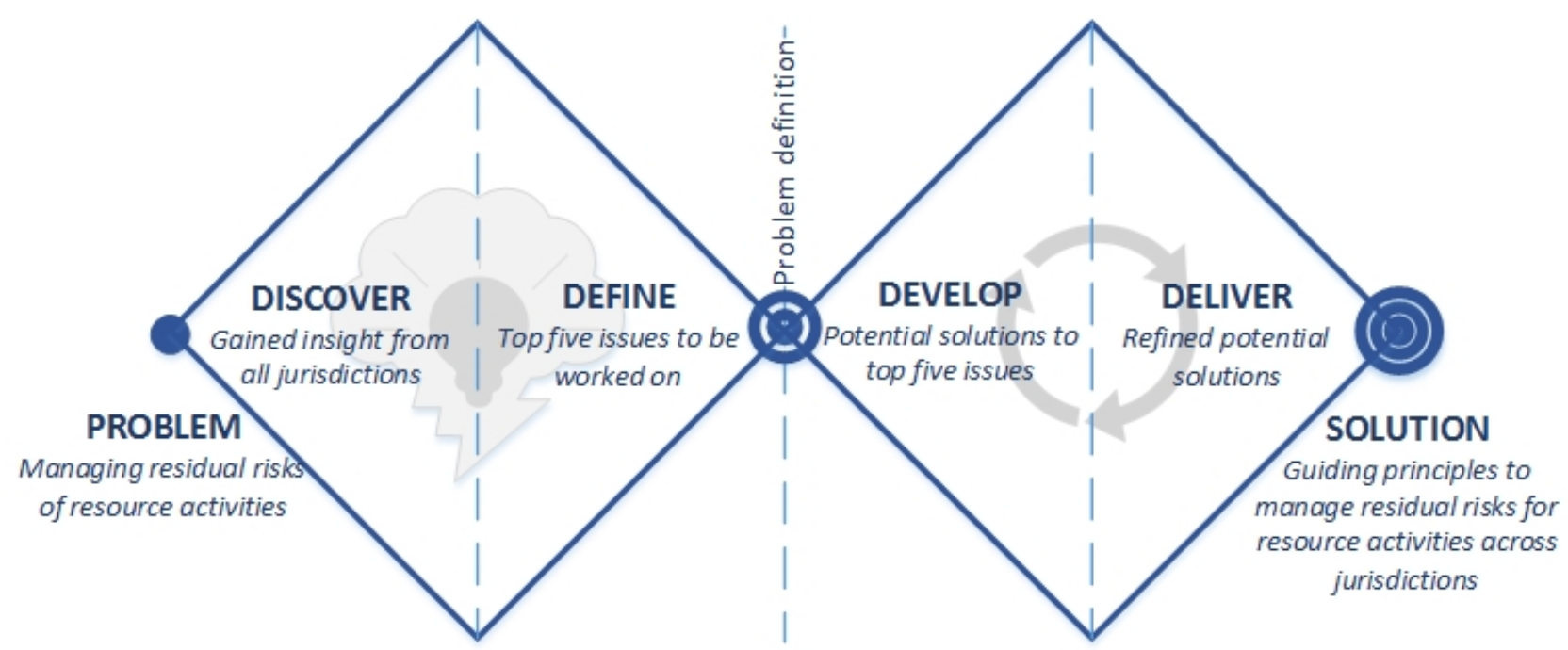

Figure 1 The double diamond framework detailing the workshop design

\subsubsection{Design thinking}

Design thinking is a methodology that uses a solution-based approach to solving problems. There are five stages to the design thinking process, show in Figure 2. The design thinking process for the workshop is based on the design thinking approach practised by IDEO (IDEO ca.2008).

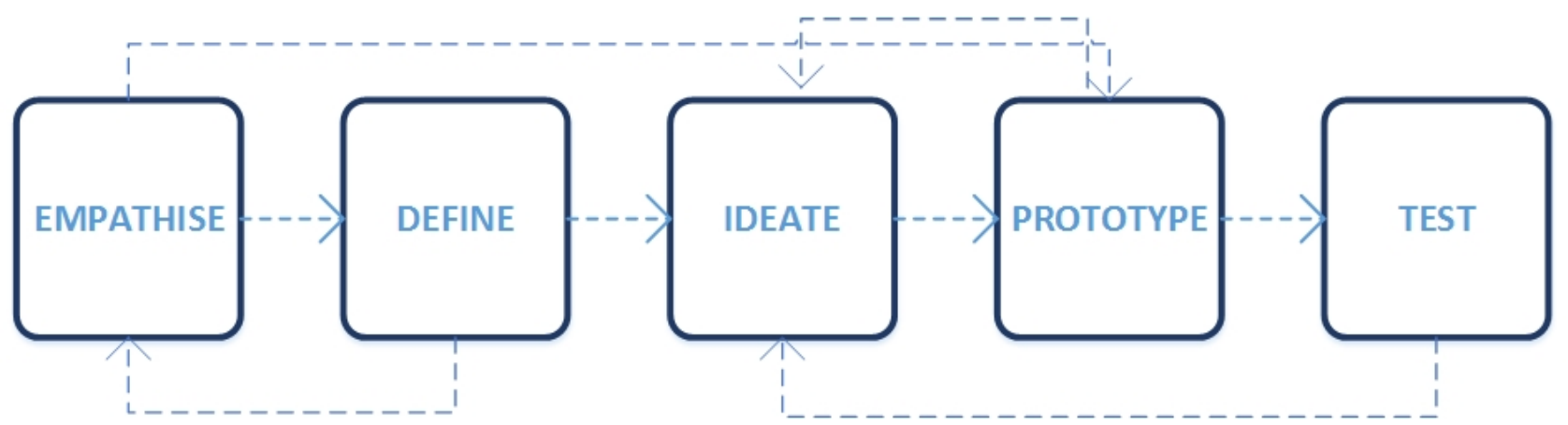

Figure 2 Steps in design thinking (adapted from Interaction Design Foundation 2019)

\subsubsection{Empathise}

The first stage of the design thinking process is to gain an empathic understanding of the problem to be solved, aligning with the first stage of the double diamond framework, 'discover'. For the workshop, this involved consulting officers from each jurisdiction to gain a better understanding about how residual risks are currently managed. Accent Environmental was also consulted to provide participants with a better understanding of a potential cost estimation methodology. The process allowed all officers to have the best possible understanding of the jurisdictions for which the principles were being designed. Officers were also asked to 'vote with their feet', showing which of the issues listed in Section 2.1 were important to them and explaining why.

Based on what was learnt during this stage, the 'vote with your feet' activity and the issues selected by jurisdictions prior to the workshop, provided in Section 2.1, the following amended or additional issues were chosen to consider for Day 2:

- What site features should be considered, including transferring assets to landholders-should assets still be considered in residual risk payment?

- Application of residual risk. 
Participants were then asked to select an issue that they would like to work on, and they were grouped accordingly for Day 2.

\subsubsection{Define}

During the 'define' stage of the design thinking process and double diamond framework, participants used the information gathered in the 'empathise' phase to analyse observations and synthesise them to define the core problems for the top five issues nominated on Day 1. Participants were asked to define the problem, consider why it exists and why solving it matters and define the opportunity.

When defining the problem participants were asked to discuss and answer the following questions:

1. What is not working for whom? (i.e. problem statement)

2. What is the most compelling quantitative insight that supports your problem statement?

3. What is the most compelling qualitative insight from users/stakeholders that supports your problem statement?

When defining why, participants were asked to discuss and answer the following questions:

1. Why does the problem exist? Participants were instructed to ask why at least five times to get to the core issue.

2. Why does solving it matter? Participants were instructed to ask why at least five times to get to the core reason.

When defining the opportunity participants were asked to discuss and answer the following question:

1. How might we...? Participants were asked to define the optimistic vision for a future that users and stakeholders could experience if the problem was solved.

\subsubsection{Ideate}

During the 'ideate' phase all participants started to 'think outside the box' to identify new solutions by brainstorming the best and worst possible ideas for each issue. This phase also aligned with the 'develop' stage of the double diamond framework. The 'ideate' stage stimulated individual freethinking and allowed participants to develop as many ideas as possible. Participants were given 10 minutes each, and post-it notes, to identify their best and worst possible ideas.

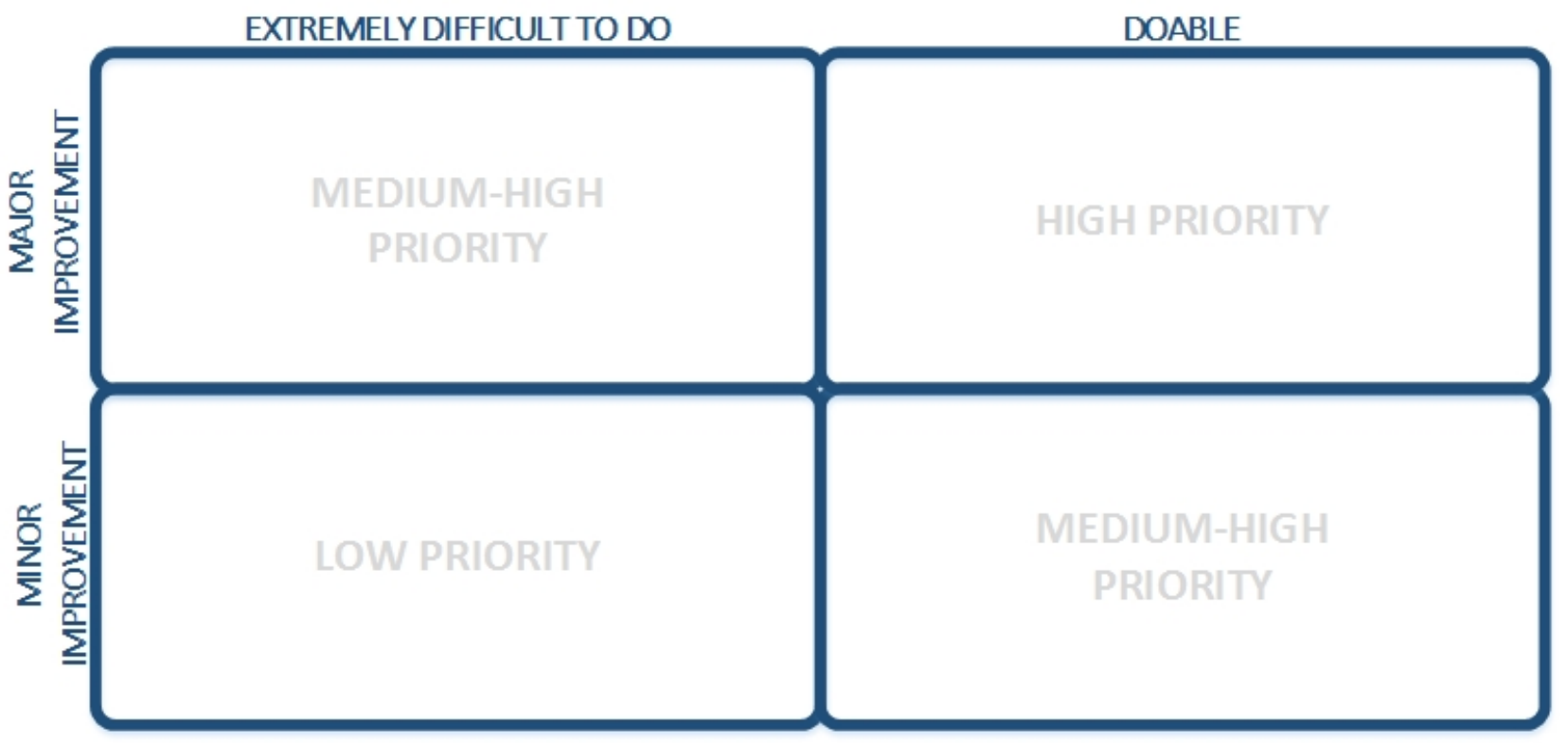

Figure 3 Problem prioritisation matrix 


\subsubsection{Prototype}

During the second part of Day 2, groups prototyped potential solutions to the top five issues, reflecting the 'deliver' stage of the double diamond framework. Participants were asked to test the majority of the solutions proposed in the 'ideate' phase by considering various stakeholder perspectives. Each group of participants nominated a stakeholder group to emulate based on an unbiased definition of each stakeholder type. Stakeholders considered included industry, the public, conservation groups, landholders and the media.

Based on the stakeholder feedback of the solutions, the ideas were then categorised into the prioritisation matrix provided in Figure 3.

The matrix (Figure 3) also allowed participants to test the ability of their solutions to be implemented. Following the use of the matrix, groups chose the three best options for their issue. These options were then considered when developing the guiding principles. In some cases, groups defined fewer than three options.

To ensure the guiding principles were high level and could be used across jurisdictions, the three best options from each table were considered at a strategic level. Using these options and a set of principles previously drafted by Victoria, a set of statements were synthesised for use in further prototyping, as detailed in Section 2.3. The participants of the workshop then produced a number of potential guiding principles. These were investigated further through discussion, questioning and consideration of implementation.

\subsubsection{Test}

During the test phase, the solutions (three best options and guiding principles) will be rigorously tested. As residual risk policy is under development in most jurisdictions, the principles will be tested over time. As design thinking is an iterative process the results generated during this phase may be used to redefine one or more problems, or principles. As the principles are used more across jurisdictions, they may change to reflect current policy settings. As well as continual engagement, Queensland intends to review the practical application of the principles after residual risk policies and frameworks are finalised and share learnings with other jurisdictions.

\subsection{Development of draft principles}

Day 3 of the workshop employed simple facilitation techniques to deliver draft guiding principles. Using previous principles drafted by a Victorian participant, other principles that had been observed during the workshops, key words that had come up, the three best options for each issue as well as themes that had arisen during the course of the workshop, participants, in groups, were asked to pull together a 'prototype' of a set of principles. In total participants were given approximately 40 statements, printed and cut into individual pieces of paper.

Participants were split into groups, different to those from Day 2 and provided statements to assist in prototyping guiding principles. A few of the examples of statements are provided below:

- Polluter pays: The full cost of transferred liability is accounted for and reflected in a funding contribution.

- State Specific: The policy is sensitive to requirements specific to each state such as the relative scale of the state's mining sector and population density requirements.

- Minimal Regulatory Burden: Where possible, regulatory burden is minimised and contributions are collected during periods of project income streams.

- Administratively Efficient: The model minimises administrative burden to both government and industry wherever possible. 
- Sustainable: The fund mechanisms allow the generation of revenue sufficient to account for future costs in perpetuity.

- Incentivises Best Practice: Internalises external costs of mining and complements the rehabilitation framework by creating incentives for holistic rehabilitation and risk-management approaches with the lowest long-term costs.

- Regulatory Certainty: The framework is simple to navigate and apply, provides certainty to industry and the community on post-closure obligations, and minimises regulatory and administrative burden.

- Site features: A quantitative site-specific risk assessment of all site features incorporating a predetermined risk threshold.

- Transfer assets to landholders: Where there is any likelihood that the state may be called to provide funds to remedy any failure of the transferred asset, it should be included within a residual risk payment.

- Post-surrender land management plan: A plan that provides certainty on how sites will be managed post-closure with the ability to be amended in regards to new information or changed circumstances.

Each table was given approximately an hour to prepare a set of guiding principles that would be acceptable across jurisdictions. Each group then presented these principles and participants asked questions and proposed alterations. There were many commonalities between the principles proposed by each table. Incorporating any concerns raised and all commonalities the facilitator and the Queensland Department of Environment and Science officers synthesised a set of principles as outlined in Section 4.

\subsection{Outputs-detailed consideration of issues}

During Day 2 of the workshop, the nominated top five issues were explored further using the design thinking processes detailed in Section 2.2.2. A deep dive was completed on each issue and the definitions of the problem, why and opportunity and three best options for a solution are provided in Table 1. From the data below it is clear that there is a common opportunity across all issues considered which was incorporated when drafting the guiding principles. 


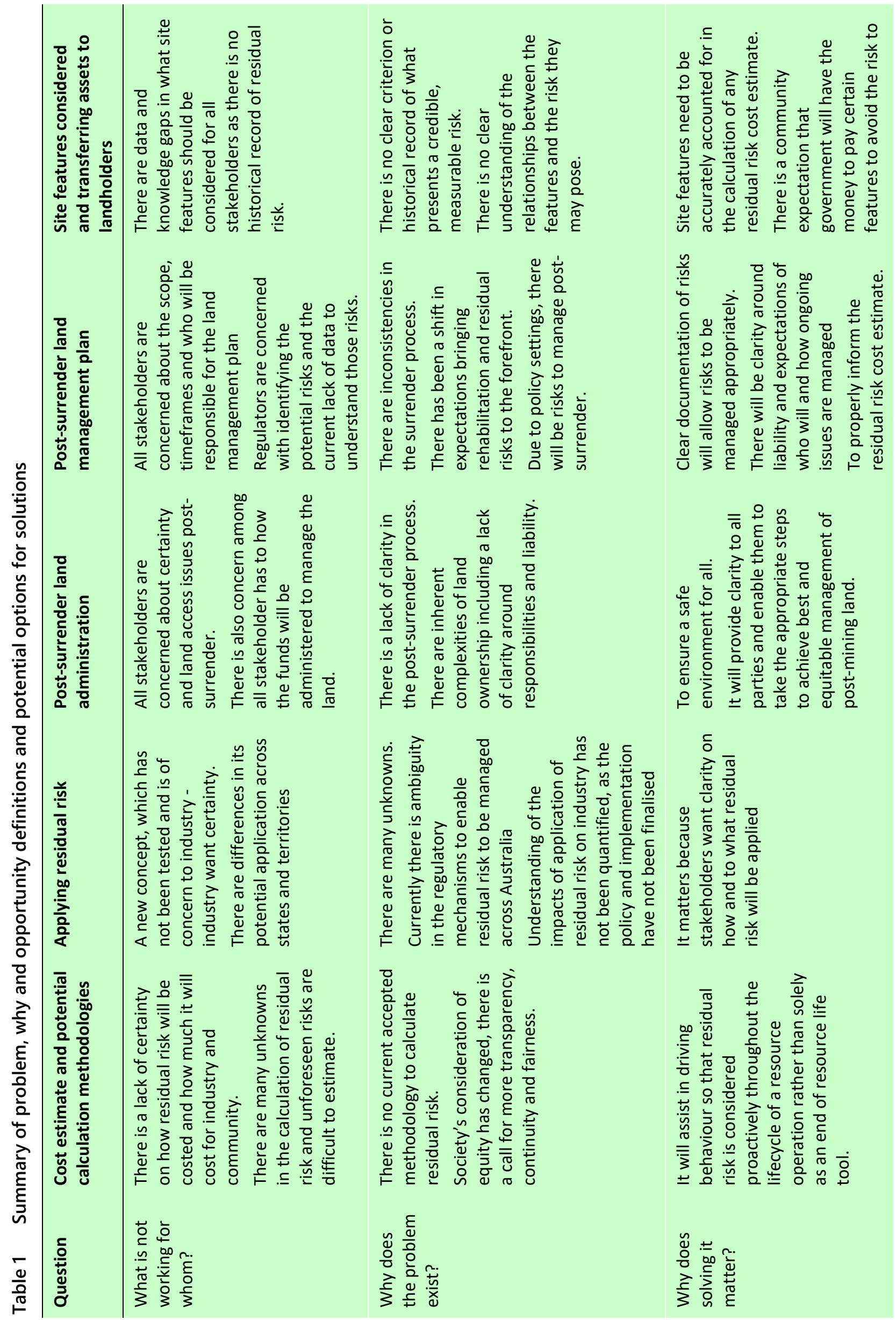




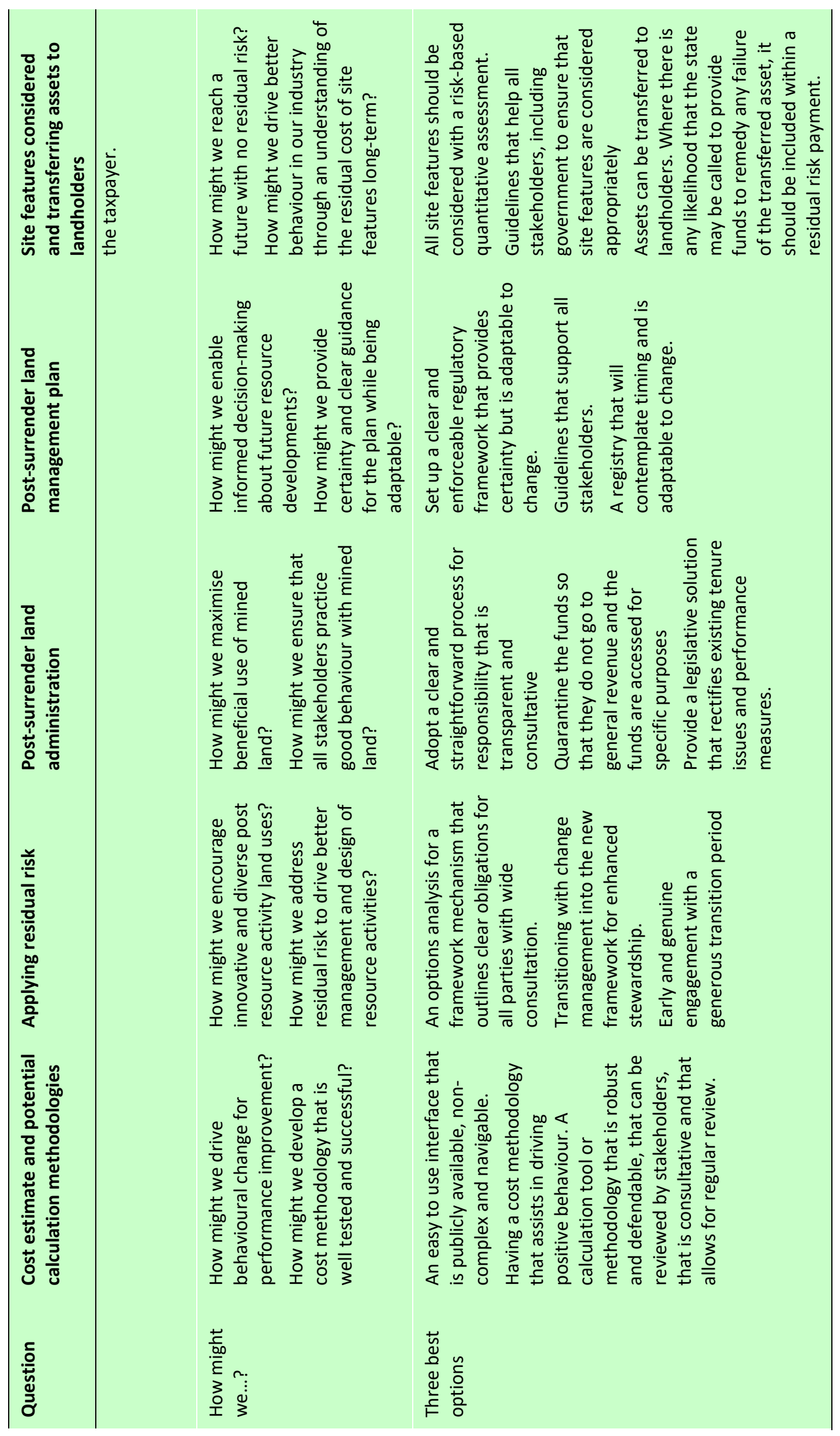




\section{Outcomes}

The objectives of the workshop were to share information about current residual risk related projects, identify common issues, opportunities and potential solutions and develop guiding principles to support coherent residual risk policy making across Australia. The outcomes of the workshop mirrored the objectives established at its inception.

The first outcome, to share information, was addressed and achieved through the pre-workshop reading and through presentations provided on Day 1 . The information sharing also played an important part in the 'empathise' or 'discover' phase allowing participants to have the best possible understanding of the issues when managing residual risks and the jurisdictions that for which the principles were being designed.

The second outcome, to identify common issues, opportunities and solutions, was achieved during Day 1 and Day 2. Prior to the workshop and throughout Day 1, common issues between jurisdictions were identified. Through the 'define' and 'ideate' or 'develop' phase the opportunities and solutions were identified. The 'prototype' phase allowed for further consideration and development of the solutions. The problem, why and opportunity definitions for each issue are detailed in Section 2.4.

The third outcome, to develop guiding principles to support coherent policymaking, was addressed on Day 3 when participants came together to prototype potential principles. As a result, the guiding principles in Section 3.1 were drafted. Feedback was received from most jurisdictions to refine these further.

\subsection{Guiding principles}

Departmental delegates across jurisdictions may consider the following guiding principles when developing complementary post-closure management policies and implementation frameworks, noting that these have not been considered for endorsement by governments:

- Design for the long-term and equity:

○ Recognise the long-term impacts of mining activities that may continue after rehabilitation and closure.

- Ensure sustainable and equitable funding arrangements to monitor, maintain and mitigate known risks and remediate unforeseen residual risks.

- Provide clarity and efficiency:

- Deliver management frameworks that are clear and simple to navigate so that industry, landholders and community understand post-closure obligations.

- Minimise the regulatory and administrative burden (to both government and industry).

- Encourage positive practice:

- Drive good planning and rehabilitation behaviours that consider whole of resource life, throughout the lifecycle of a resource operation.

- Maximise beneficial future land use opportunities by encouraging and rewarding innovation.

As part of the 'test' phase of design thinking, these principles will be put into practice, where relevant, across jurisdictions and there will likely be more iterations as residual risk policy is developed across Australia in the next 10 to 20 years.

\section{Conclusion}

The interjurisdictional workshop on managing residual risks was a successful endeavour and was beneficial to all participants. Participants in the workshop, and guest attendees, found the workshop to be constructive and agreed that it was a useful forum to discuss future policy issues. 
Throughout the workshop, it was also clear that further consideration is needed regarding how residual risk is considered on a larger scale over the life of resource activities. The structure of the workshop benefitted from the use of the double diamond framework and the design thinking process, achieving the outcomes of the workshop that were expected. As the guiding principles are tested across jurisdictions, key contacts will continue to work together to revise the guiding principles, if necessary, to ensure they remain current.

The workshop has also created a legacy. A key part of the workshop legacy was putting together this paper and presenting the interjurisdictional workshop at the 2019 Mine Closure Conference. Other legacies were the revitalisation of networking groups such as the Australian Mine Regulatory Environment Group (AMREG). AMREG was created to allow governments across Australia to share learnings on regulation of mining activities, including rehabilitation. The workshop also created a group of key contacts across jurisdictions, including those who were not able to attend, assisting in future information sharing and feedback on policy.

The workshop was also valuable in demonstrating how informal collaborative workshops similar to this are essential in creating complementary policy across Australia's states and territories. Complementary policy making across borders not only benefits regulators but also provides benefits to industry and community, setting realistic expectations, reducing confusion and streamlining processes. High-level principles such as those that were created as a part of this workshop help to achieve similar outcomes and create more standardised frameworks and governance over resource activities, reducing administrative burden on industry and regulators.

\section{Acknowledgement}

We would like to acknowledge all participants in the workshop from Queensland, New South Wales, Victoria and the Northern Territory, your time, effort and input were very valuable. We also acknowledge the facilitators, JTA Australia who were instrumental in the design and delivery of the workshop and Accent Environmental and Lane Consulting for their presentation about cost estimate methodologies at the workshop. Finally, we want to thank our colleagues at the Queensland Department of Environment and Science for their support in running the workshop, particularly Lee Coulthard, Alison O'Gorman, Annie McCabe, Barbara Oliveira De Loreto, Michael Messer and Jade Watson for being table facilitators and Celia Kearns for her efforts in preparing materials for the workshops.

\section{References}

Cooper, S 2019, 'Maximising post-mining land use: Queensland Government reforms', in AB Fourie \& M Tibbett (eds), Proceedings of the 13th International Conference on Mine Closure, Australian Centre for Geomechanics, Perth, pp. 969-982.

Government of New South Wales 1979, Environmental Planning and Assessment Act 1979, Australia.

Government of Northern Territory 2001, Mining Management Act 2001, Australia.

Government of Victoria 2019, Mineral Resources (Sustainable Development) (Mineral Industries) Regulations 2019, Australia.

Hazelwood Mine Fire Inquiry 2016, Hazelwood Mine Fire Inquiry Report 2015/2016: Volume IV-Mine Rehabilitation, viewed 2 April 2019, https://www.parliament.vic.gov.au/file_uploads/11172_HAZ_MFIReport-2015_16-Volume4_FA_LR_15B0_pQfGZRfC.pdf IDEO ca. 2008, Design Thinking Defined, viewed 22 March 2019, https://designthinking.ideo.com/

Interaction Design Foundation 2019, 5 Stages in the Design Thinking Process, viewed 22 March 2019, https://www.interactiondesign.org/literature/article/5-stages-in-the-design-thinking-process

State of Queensland 2018, Managing Residual Risks in Queensland Discussion Paper, Brisbane, https://environment.des.qld.gov.au/management/pdf/managing-residual-risks-discussion-paper.pdf

The UK Design Council 2015, The Design Process: What is the Double Diamond?, News and Opinion-Features, viewed 22 March 2019, https://www.designcouncil.org.uk/news-opinion/design-process-what-double-diamond 
